\title{
Application of Fiber Grating Monitoring Technology in Mine Excavation Work
}

\author{
Bowen Cui \\ Shandong University of Science and Technology,Mining and Safety \\ engineering institute,Shandong,Qingdao,266590, China \\ email:Iulu8472@qq.com
}

Keywords: fiber grating sensor; monitoring system; heading face; stability

\begin{abstract}
This article mainly focus on the research of the fiber grating sensor technique and the coupling characteristics with the monitoring system. First of all, it describes the form of the fiber grating monitoring system, and then describes its working mechanism and the feature. After that, begins the part of research on the essence of the fiber grating monitoring and the relevant argue, finally make a conclusion that the system can continuously, reliably and accurately monitor the stability of coal-rock mass in the coal mine.
\end{abstract}

\section{Introduction}

In our country, the superior occurrence of coal seam is gradually decreasing, the intensity of coal mining is increasing, mining environment is getting more and more complicated[1], coal and rock dynamic disasters happens unpredictable, all those circumstances are seriously threating the safety of coal production.

Coal roadway tunneling faces is the main places of coal and rock dynamic disaster happens, because the coal and rock excavation is often to environment that relatively unknown, which makes the accident prevention and control a great difficulty. At present, the industry is still lack of effective means of real-time safety monitoring; early warning mechanism is hard to be established.

In recent years, with the development of smart sensing materials, high-performance sensors and testing technology for the study of the structure of the intelligent monitoring system provides a new approach[2].

Fiber Bragg grating sensor has characteristics of a long-term stable performance, high observation precision, can work over a wide range temperature. The embedded structure of the material internal stress and strain distribution in the real-time monitoring provides a new method for the study of the stability of the disturbance of coal of rock mass.

\section{Fiber Bragg grating monitoring system}

FBG monitoring system consists of optical fiber grating sensor network, optical fiber grating demodulation devices and data acquisition computer. Compared with the commonly used strain sensor, fiber grating sensors to this system have advantages of the quality and size, high precision, good long-term stability, corrosion resistance, and distributed setting. 


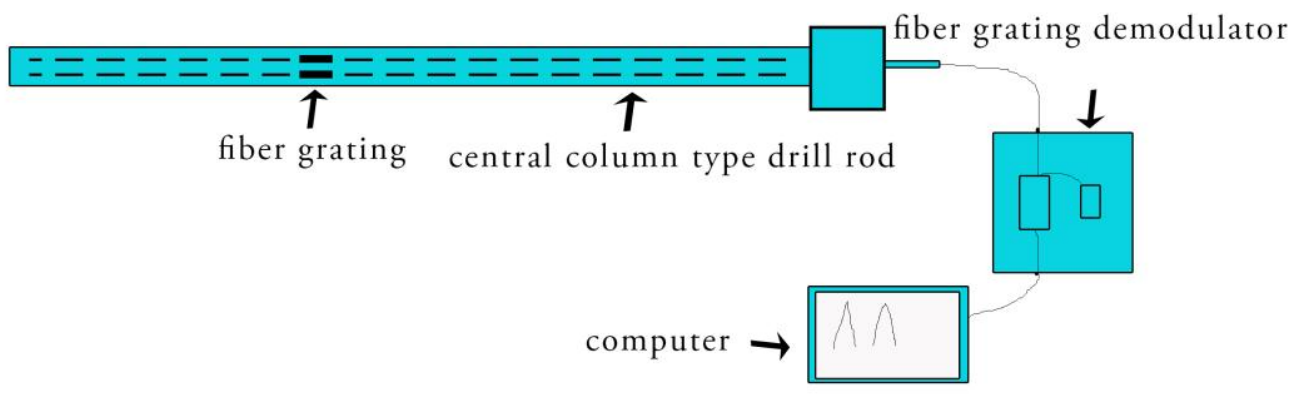

Figure 1. The diagram of fiber grating monitoring system

\section{Working principle and characteristics of fiber Bragg grating monitoring system}

Roadway drivage has complex disturbance to the original stress state and damage degree of coal, fiber Bragg grating sensing system through the internal structure of the small deformation of coal or rock to stretch or compression fiber Bragg grating, and thus achieve the goal of change reflection wavelength of fiber grating[3][4]. Fiber Bragg grating center wavelength drift amount and the measured changes of the internal structure of the small deformation of coal or rock amount are into a linear relationship. Based on these characteristics, of manufacturing on the basis of the principle of fiber Bragg grating sensors by the wavelength of light collection value can be real-time calculated stress variation in the corresponding physical quantities - size. Thus, to achieve automatic measurement of coal and rock tunneling faces, data storage, and long distance transmission by cables, to predict the buckling critical value of lost control during the mining work.

When roadway drivage forward, the original coal is in dynamic equilibrium, when the equilibrium is broken, according to the mine pressure theory[5], the shift to two vertical stress and horizontal stress concentrated to the roof and floor, high concentrated stress lead to deformation and broken and form a fracture pressure relief area; Then shift to the deep of coal to achieve a new equilibrium. According to characteristics of the internal force distribution roof and floor, unloading fracture zone in front of tunneling faces range of 0 to $2 \mathrm{~m}$, stress, high for 2-11 $\mathrm{m}$. Thus we arrange two drill empty, a near the roof, roof distance 0.30 .5 meters, the one on the side to help, for 4 to 5 $\mathrm{m}$ distance side. Using center through cable type drill pipe to the location of the fiber grating needed, to realize intelligent monitoring purposes. Layout diagram as shown below:

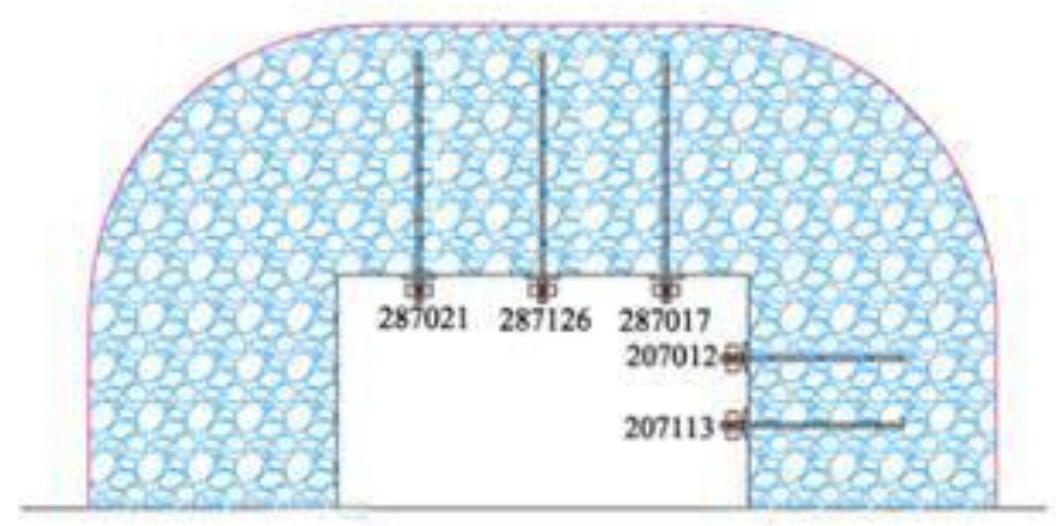

Figure 2. The diagram of borehole layout 
This technology uses the geological drilling rig start working at one side of the drilling face, use free telescopic drill pipe to push the cable to the end of fiber grating sensing equipment, and connect to the computer to acquit stress value of the coal seam ahead. As shown in the figure below:

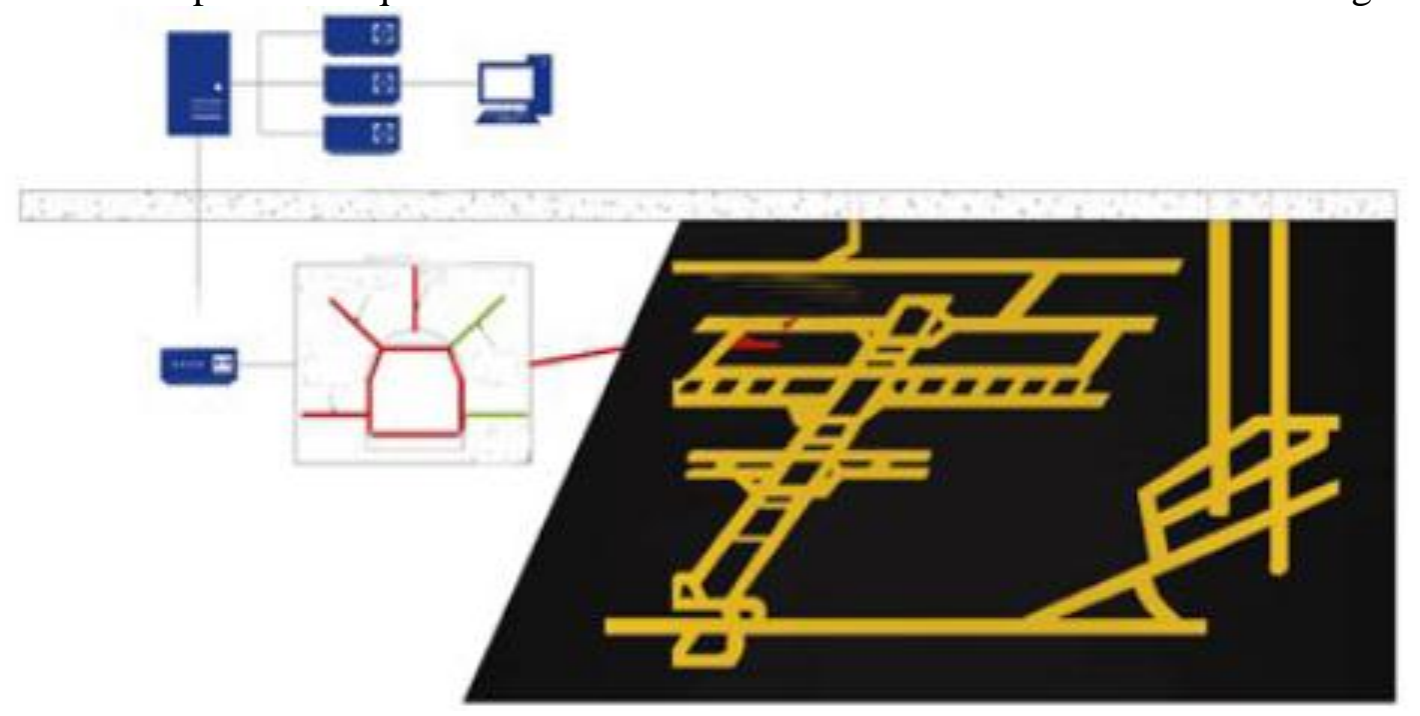

Figure 3. The diagram of fiber grating monitoring system in surrounding rock mining

\section{Conclusions}

Due to its features of long-term stability, precision of good performance, firm structure, moisture, proof, work over a wide range temperature, the FBG monitoring system has been widely used in mine excavating, solve the current situation of the coal and rock stress state real-time monitoring, not only improve the safety and reliability of the structure of coal or rock tunneling faces, but also can reduce the structure of the operation and maintenance cost, which has a significant economic value.

\section{References}

[1] China Investment Guide. Coal can available only 33 years in China.

[EB/OL].http://www.fdi.gov.cn/1800000121_21_53311_0_7.html.

[2]Chuangxin Lv. Application of Fiber Grating Dynamometry Bolt in Coal Mine Tunnel Surrounding Rock Monitoring [J]. Chinese Science and Technology Paper,2015,8 (16) : 17511760.

[3] Jifeng Chen,Dongsheng Xie, Shaolan Zhang. Application of FBG Monitoring System in the Main Structure of Concrete[J]. Waterway Engineering,2011,8(456):70-72.

[4] Jie Zhu. Research on Monitoring System of Fiber Bragg Grating Tunnel[D]. Master's Degree Thesis of Shandong University.JiNan: Shandong University,2006.

[5] Anmin Wu. Energy Saving Application of Frequency Conversion Speed Regulation in Coal Mine Main Fan [C]. Zheng Coal Group Xinmi Branch. Ventilation, Drainage. Proceedings of the sixth annual conference of Henan Coal Society. Henan: 2012: 246-250. 